\title{
Inhaled corticosteroids for chronic obstructive pulmonary disease: what is their role in therapy?
}

This article was published in the following Dove Press journal:

International Journal of COPD

\author{
Donald P Tashkin' \\ Charlie Strange ${ }^{2}$ \\ 'Department of Medicine, David \\ Geffen School of Medicine, University \\ of California, Los Angeles, CA, USA; \\ ${ }^{2}$ Department of Pulmonary and \\ Critical Care Medicine, Medical \\ University of South Carolina, \\ Charleston, SC, USA
}

\begin{abstract}
Inhaled corticosteroids (ICSs) are a mainstay of COPD treatment for patients with a history of exacerbations. Initial studies evaluating their use as monotherapy failed to show an effect on rate of pulmonary function decline in COPD, despite improvements in symptoms and reductions in exacerbations. Subsequently, ICS use in combination with long-acting $\beta_{2}$-agonists (LABAs) was shown to provide improved reductions in exacerbations, lung function, and health status. ICS-LABA combination therapy is currently recommended for patients with a history of exacerbations despite treatment with long-acting bronchodilators alone. The presence of eosinophilic bronchial inflammation, detected by high blood eosinophil levels or a history of asthma or asthma-COPD overlap, may define a population of patients in whom ICSs may be of particular benefit. Prospective clinical studies to determine an appropriate threshold of eosinophil levels for predicting the beneficial effects of ICSs are needed. Further study is also required in COPD patients who continue to smoke to assess the impact of cell- and tissue-specific changes on ICS responsiveness. The safety profile of ICSs in COPD patients is confounded by comorbidities, age, and prior use of systemic corticosteroids. The risk of pneumonia in patients with COPD is increased, particularly with more advanced age and worse disease severity. ICS-containing therapy also has been shown to increase pneumonia risk; however, differences in study design and the definition of pneumonia events have led to substantial variability in risk estimates, and some data indicate that pneumonia risk may differ by the specific ICS used. In summary, treatment with ICSs has a role in dual and triple therapy for COPD to reduce exacerbations and improve symptoms. Careful assessment of COPD phenotypes related to risk factors, triggers, and comorbidities may assist in individualizing treatment while maximizing the benefit-to-risk ratio of ICS-containing COPD treatment.
\end{abstract}

Keywords: COPD, inhaled corticosteroids, bronchodilators, dual/triple therapy, safety, pneumonia

\section{Plain-language summary}

Increasing treatment options for COPD add to the complexity of treatment and require review of clinical data to inform treatment decisions. Inhaled corticosteroids (ICSs) in combination with long-acting $\beta_{2}$-agonists (LABAs) reduce the risk of exacerbations and improve lung function and health status in patients with COPD compared with ICS or LABA therapy alone. Certain patients may particularly benefit from ICS therapy, including those with frequent exacerbations despite long-acting bronchodilator therapy and those with evidence of eosinophilic bronchial inflammation, which can be determined by high levels of blood eosinophils and/or a history of asthma or asthma-COPD overlap. Although relatively uncommon, an increased risk of pneumonia is associated with ICS use and appears to be dependent on the specific ICS used. Recent studies of triple therapy combining an ICS, LABA, and a long-acting muscarinic antagonist demonstrated significant benefits compared with dual therapy and support their widespread use
Correspondence: Donald P Tashkin Department of Medicine, David Geffen School of Medicine at UCLA, 10833 Le Conte Avenue, Los Angeles, CA 90095, USA

$\mathrm{Tel}+13108253163$

Fax + I 3102065088

Email dtashkin@mednet.ucla.edu (c) (1) (9) 2018 Tashkin and Strange. This work is published and licensed by Dove Medical Press Limited. The full terms of this license are available at https://www.dovepress.com/terms.php

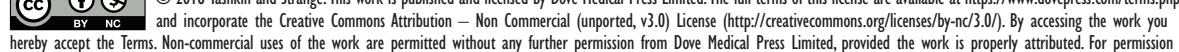
for commercial use of this work, please see paragraphs 4.2 and 5 of our Terms (https://www.dovepress.com/terms.php). 
in COPD patients with frequent exacerbations, but longer-term data and comparisons of specific triple-therapy regimens are needed to optimize therapy.

\section{History of inhaled corticosteroid use in COPD}

COPD is characterized by persistent respiratory symptoms and progressive airflow limitation. ${ }^{1}$ Goals of COPD management are to minimize the impact of symptoms, improve levels of physical activity, and decrease the future risk of exacerbations responsible for disease progression. ${ }^{1}$ Achieving these goals is challenging due to the heterogeneous nature of COPD and an incomplete understanding of the pathophysiology of the disease. Inflammatory changes have been observed in the lungs as a result of inhaling cigarette smoke, as well as noxious particles and gases from other sources. ${ }^{1}$ The presence of increased numbers of inflammatory cells in airway biopsies and bronchoalveolar lavage, including neutrophils, alveolar macrophages, and T lymphocytes, in the lungs of smokers susceptible to the development of COPD may act directly on airway and alveolar tissue, promoting airway narrowing and airflow limitation. ${ }^{2,3}$ These data, in conjunction with the effectiveness of inhaled corticosteroids (ICSs) in the treatment of asthma, encouraged routine use of ICSs in patients with COPD. Over the past three decades, extensive research has been conducted evaluating the use of ICSs in such patients. This article reviews the history of the use of ICSs in COPD, with a focus on pivotal clinical studies, systematic reviews, and meta-analyses. The effect of smoking on ICS response in COPD is also discussed, and safety considerations for ICS use in COPD are examined, particularly regarding long-term safety and pneumonia risk. The applicability of these data is considered in light of current treatment practices, as well as their relevance to future therapy for COPD, including triple-therapy regimens.

\section{Use of ICS monotherapy in COPD}

In the 1990s, short-term studies of ICS monotherapy in patients with COPD and chronic bronchitis found that antiinflammatory therapy reduced bronchial inflammation, but had varying effect on lung-function measures of forced expiratory volume in 1 second $\left(\mathrm{FEV}_{1}\right)$ and peak expiratory flow (PEF). ${ }^{46}$ In a 6-month study, fewer exacerbations, particularly the most severe exacerbations, occurred in patients treated with ICSs compared with placebo. ${ }^{6}$ Subsequently, four long-term (3-year) randomized, placebo-controlled studies of ICS in patients with COPD were conducted to determine the effect of therapy on the rate of decline in pulmonary function, the results of which are discussed further herein..$^{7-10}$ These studies identified varying effects of ICSs on outcomes of interest in COPD, but failed to show benefit of ICS monotherapy on pulmonary function (Table 1). A meta-analysis of ICS studies investigating lung function in patients with COPD showed that ICS use did not slow the rate of $\mathrm{FEV}_{1}$ decline in 3,571 patients over 24-54 months. ${ }^{11}$ In addition, a subsequent pooled analysis of 3,911 patients showed that after 6 months, ICS therapy did not modify FEV decline in patients with moderate-severe COPD. ${ }^{12}$

\section{Lung Health Study II}

Participants from the Lung Health Study smoking-cessation trial were recruited for a second study to assess the effect of triamcinolone acetonide in delaying decline in lung function in participants with COPD. ${ }^{7}$ A total of 1,116 smokers (or those who had quit smoking within the prior 2 years) with airflow obstruction, defined as an $\mathrm{FEV}_{1}$ to forced vital capacity (FVC) ratio $<0.70$ and $\mathrm{FEV}_{1} 30 \%-90 \%$ predicted, were enrolled. Although asthma diagnosis was not technically an exclusion criterion, patients who used bronchodilators or ICSs regularly were excluded, effectively excluding those with symptomatic asthma. The primary outcome measure, rate of decline in postbronchodilator $\mathrm{FEV}_{1}$, showed no significant effect of ICS treatment vs placebo (44.2 vs $47.0 \mathrm{~mL}$ per year, respectively). Most respiratory symptoms, including cough, phlegm, wheezing, and breathlessness, over the preceding year did not differ significantly between treatment groups at 36 months. Fewer new or worsening respiratory symptoms were found in the ICS group. The rate of unscheduled physicians' visits and hospitalization for respiratory conditions was lower in the ICS group, but visits to the emergency department (for respiratory and nonrespiratory conditions) and all health-care visits (for nonrespiratory conditions) were similar between treatment groups. At baseline, airway reactivity was similar between groups. At 9 and 33 months, the ICS group had significantly less reactivity to methacholine challenge than placebo $(P=0.02)$. Overall, health-related quality of life (measured by the SF36) showed no changes associated with treatment, except for a slightly worse mental health subscale score at 36 months in the ICS group compared with placebo.

\section{European Respiratory Society study on COPD}

Across nine European countries, 1,277 smokers aged 30-65 years with postbronchodilator $\mathrm{FEV}_{1} 50 \%-100 \%$ predicted and prebronchodilator $\mathrm{FEV}_{1}$ : slow vital capacity ratio $<70 \%$ were randomized to receive budesonide dry-powder inhaler or placebo for 3 years. ${ }^{8}$ Patients with a history of asthma 


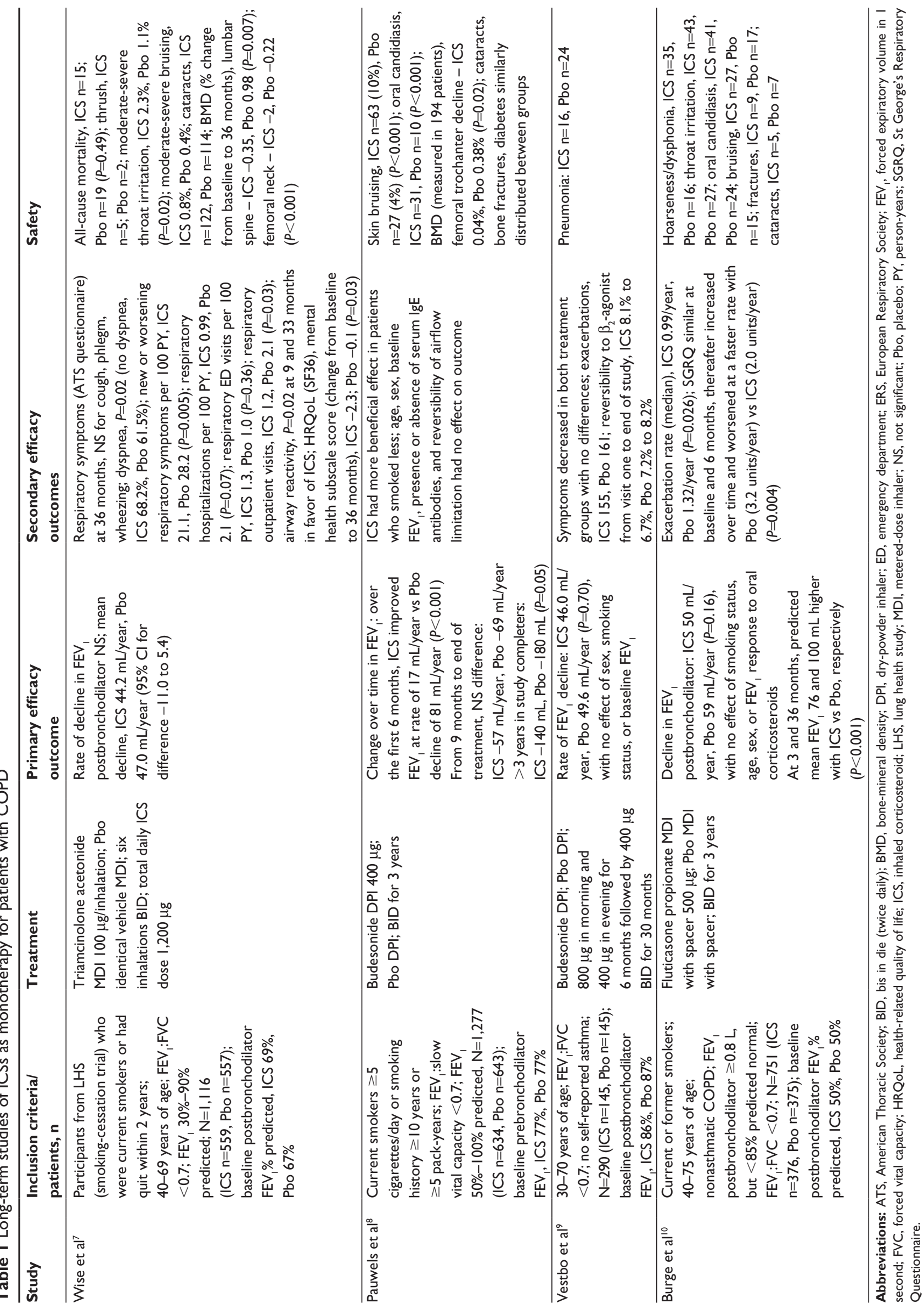


were excluded. Changes in postbronchodilator $\mathrm{FEV}_{1}$ over the first 6 months were significantly different between ICSs (improved at a rate of $17 \mathrm{~mL} /$ year) and placebo (declined by a rate of $81 \mathrm{~mL} /$ year, $P<0.001$ ); however, by 9 months the slopes of $\mathrm{FEV}_{1}$ decline were similar between treatment groups $(P=0.39)$. Among those who completed the 3-year study ( $\mathrm{n}=912)$, the median decline in $\mathrm{FEV}_{1}$ over 3 years was $140 \mathrm{~mL}$ in the ICS group and $180 \mathrm{~mL}$ in the placebo group $(P=0.05)$. ICS use was more effective in patients who smoked less, but there was no association of the slope of $\mathrm{FEV}_{1}$ decline with age, sex, baseline $\mathrm{FEV}_{1}$, presence/absence of serum IgE antibodies, or reversibility of airflow limitation.

\section{Copenhagen City Lung Study}

Participants in the Copenhagen City Heart Study were eligible for the lung study if they were aged 30-70 years, had an $\mathrm{FEV}_{1}: \mathrm{FVC}$ ratio $\leq 0.7$, and had no self-reported asthma. ${ }^{9}$ Smoking history was not an inclusion criterion, and long-term CS treatment (more than two episodes of $>4$ weeks duration) was the main exclusion criterion. A total of 290 patients were randomized to budesonide or placebo. There was no significant effect of ICSs on rate of $\mathrm{FEV}_{1}$ decline, and stratification by sex, smoking status, and baseline $\mathrm{FEV}_{1}$ did not affect these results. No significant differences were observed between treatment groups for occurrence of symptoms, exacerbations, or reversibility to $\beta_{2}$-agonist treatment.

\section{Inhaled Steroids in Obstructive Lung Disease in Europe (ISOLDE) study}

Current or former smokers aged 40-75 years with nonasthmatic $\mathrm{COPD}, \mathrm{FEV}_{1}$ :FVC ratio $<70 \%$, baseline postbronchodilator $\mathrm{FEV}_{1} \geq 0.8 \mathrm{~L}$ but $<85 \%$ predicted were eligible for the ISOLDE study. ${ }^{10}$ A total of 751 patients were randomized to fluticasone propionate or placebo. No significant difference in annual rate of $\mathrm{FEV}_{1}$ decline was observed between ICSs and placebo (50 vs $59 \mathrm{~mL} /$ year, $P=0.16$ ), and slopes of decline were not influenced by smoking status, age, sex, or $\mathrm{FEV}_{1}$ response to oral CSs. The predicted mean $\mathrm{FEV}_{1}$ at 3 and 36 months was significantly higher with ICSs by 76 and $100 \mathrm{~mL}$, respectively, vs placebo $(P<0.001)$. The median yearly exacerbation rate was $25 \%$ lower for ICS vs placebo ( 0.99 vs 1.32 per year, $P=0.026)$. In both treatment groups, health status measured by the disease-specific St George's Respiratory Questionnaire (SGRQ) improved after the first 6 months of treatment (slight decrease in SGRQ total score), but thereafter it worsened (increase in SGRQ score), and the rate of worsening was slower with ICSs than placebo (increase of 2.0 vs 3.2 units/year, respectively, $P=0.004$ ).

The results of these four studies consistently showed that ICS monotherapy did not reduce the accelerated rate of decline in pulmonary function that is characteristic of COPD, and thus ICS monotherapy is not disease-modifying. The only therapy proven to slow $\mathrm{FEV}_{1}$ decline in COPD is smoking cessation. ${ }^{13}$ However, ICSs improved some key secondary outcomes, including COPD symptoms, health-care utilization, airway reactivity, and notably the frequency of exacerbations. Systematic reviews of randomized controlled trials with at least 6 months of follow-up comparing ICS monotherapy vs placebo found a statistically significant reduction (18\%-24\%) in risk of exacerbations with ICSs. ${ }^{14,15}$ Moreover, when the reduction in exacerbation risk by ICSs was regressed against initial $\mathrm{FEV}_{1}$ percentage predicted, it was found that the more severe the airflow obstruction, the greater the risk reduction. ${ }^{14}$ In addition, ICS therapy was also shown to decelerate the rate of worsening of health status measured by the SGRQ, with a 1.4-unit improvement (decrease in SGRQ score) relative to placebo. ${ }^{14}$ A Cochrane database review of randomized controlled trials comparing ICSs and placebo also showed the effect of ICSs on reducing exacerbations and slowing the rate of decline in healthrelated quality of life. ${ }^{16}$ The ICS effect was not predicted by oral CS response, bronchodilator reversibility, or bronchial hyperresponsiveness.

The net impact of these studies in today's world of combination therapy for COPD is that effects of CSs, at least when administered alone, are often slow to develop, and responses in the first 6 months of therapy may not remain the same in the long term. Far fewer studies have been done on the effect of CS withdrawal in COPD, and few current combination-therapy studies require a 6-month washout prior to initiation of the trial.

Barnes et al reviewed cellular and molecular mechanisms of COPD pathogenesis and proposed several factors that may explain the limited response to ICS monotherapy in this disease. ${ }^{17,18}$ ICSs or oral CSs do not suppress inflammation in COPD, even at high dosages. In COPD, the numbers of airway neutrophils are increased, but they are not fully suppressed by CSs. In addition, resistance to CSs may be related to decreased activity and expression of HDAC2 in inflammatory cells of patients with COPD as a result of increased oxidative and nitrative stress from cigarette smoking. ICSs may have a small bronchodilator effect that is not disease-modifying, but additional investigation is warranted. The lack of significant efficacy on the rate of decline of $\mathrm{FEV}_{1}$ may have prevented 
exploration of the dose response for ICSs in COPD. ${ }^{1}$ In 2014 , a randomized, prospective study compared two dosages of fluticasone (500 and 1,000 $\mu \mathrm{g} /$ day) in patients with COPD and an $\mathrm{FEV}_{1}: \mathrm{FVC}$ ratio $<70 \%, \mathrm{FEV}_{1}<80 \%$ predicted, and smoking history $>10$ pack-years. ${ }^{19}$ The higher dosage was associated with improved lung function and symptoms, decreased exacerbations, and better quality of life compared to the lower dosage. In asthma, there is a tendency to administer higher dosages of ICS than needed for symptom control; however, this may increase the risk of adverse events, such as adrenal suppression, osteoporosis, and growth inhibition in children. ${ }^{20,21}$ Therefore, for US Food and Drug Administration (FDA) regulatory approval, efficacy differences between dosage groups must be demonstrated for COPD. ${ }^{22}$

\section{Use of ICSs in combination with LABAs}

Combining drugs with different modes of action may improve outcomes. Two-way synergistic activity between ICSs and LABAs has been demonstrated. ${ }^{23,24}$ One of the cellular actions of ICSs is to translocate glucocorticoid receptors from the cytoplasm to the nucleus. ${ }^{24}$ This action is enhanced in the presence of $\beta$-agonists and causes an anti-inflammatory effect greater than either drug alone, without the need to increase the ICS dosage. ${ }^{23}$ In addition, ICSs activate $\beta$-receptor genes to produce more $\beta$-receptors, thereby enhancing the bronchodilator effect of LABAs. ${ }^{25}$ Numerous clinical studies have been conducted evaluating ICS-LABA combinations in patients with COPD, and systematic reviews and meta-analyses have pooled their results to inform treatment decisions. Relevant studies are discussed in the following paragraphs.

The Towards a Revolution in COPD Health (TORCH) trial was a pivotal, double-blind, placebo-controlled, randomized study comparing salmeterol plus fluticasone propionate (50 and $500 \mu \mathrm{g}$, respectively, taken twice daily) with each component alone and placebo over 3 years. ${ }^{26}$ Patients with COPD were enrolled if they had at least a 10-pack-year smoking history, $\mathrm{FEV}_{1}<60 \%$ predicted, and an $\mathrm{FEV}_{1}: \mathrm{FVC}$ ratio $\leq 0.70 .{ }^{26}$ Among 6,184 randomized patients, the risk of death was reduced by $17.5 \%$ with the ICS-LABA combination vs placebo $(P=0.052)$. ICS-LABA significantly reduced the rate of exacerbations by $25 \%$ compared with placebo $(P<0.001)$ and improved health status and $\mathrm{FEV}_{1}$ compared with either component alone or placebo. A subsequent double-blind, randomized, parallel-group study included patients aged $\geq 40$ years with COPD who had at least a 10 -pack-year smoking history, $\mathrm{FEV}_{1}: \mathrm{FVC}$ ratio $\leq 0.70$, $\mathrm{FEV}_{1} \leq 50 \%$ predicted, and at least one exacerbation in the past year requiring oral CSs, antibiotics, or hospitalization. ${ }^{27}$ Among 782 randomized patients, a $30.5 \%$ reduction in mean annual rate of moderate-severe exacerbations was observed with salmeterol plus fluticasone propionate (50 and $250 \mu \mathrm{g}$, respectively) compared with salmeterol alone $(P<0.001)$ at half the dose of fluticasone propionate used in the TORCH study.

In a 2003 review of three ICS-LABA combinationtherapy studies in COPD patients, a 30\% reduction in exacerbations was observed vs placebo and trough $\mathrm{FEV}_{1}$ improved vs placebo (101 mL/year, 95\% CI 76-126) or either therapeutic agent alone (ICS $50 \mathrm{~mL} /$ year, 95\% CI 26-74; LABA $34 \mathrm{~mL} /$ year, 95\% CI 11-57). ${ }^{14}$ In two Cochrane database systematic reviews, ICS-LABA combination therapy administered in a single inhaler was compared to LABA or ICS monotherapy. ${ }^{28,29}$ Across nine eligible studies comparing ICS-LABA to LABA alone, the exacerbation rate was reduced by $24 \%$ ( $95 \%$ CI $0.68-0.84)$ with combination therapy, but there was no difference in mortality (OR 0.92, 95\% CI 0.76-1.11). ${ }^{28}$

In six studies that compared ICS-LABA vs ICS monotherapy, a significant $13 \%$ reduction in the rate of exacerbations was noted (RR $0.87,95 \%$ CI 0.80-0.94) and the odds of death were significantly lower with combination therapy (OR 0.78 , 95\% CI 0.64-0.94). ${ }^{29}$ In addition, a 2014 Bayesian network meta-analysis evaluated randomized controlled trials of at least 12 weeks duration comparing fixed-dose ICS-LABA combinations with active control or placebo, and found that ICS-LABA reduced moderate-severe exacerbations, with the exception of beclomethasone dipropionate-formoterol, which had the lowest sample size of all groups (Figure 1). ${ }^{30}$ HRs ranged from 0.59-0.92 for ICS-LABA vs placebo and 0.63-0.98 for ICS-LABA vs LABA monotherapy. Mediumand high-dose ICS-LABA combinations were similarly effective in reducing the rate of moderate-severe exacerbations.

Estimates of treatment effect across these systematic reviews may have differed as a result of clinical trial heterogeneity, particularly with regard to baseline exacerbation history and lung function and how a COPD exacerbation was defined within a study. ${ }^{29,31}$ Despite these differences, a clear effect of ICS-LABA combination therapy on exacerbations was demonstrated, and the Global Initiative for Chronic Obstructive Lung Disease (GOLD) 2018 report concluded that ICS-LABA combination therapy was more effective than either agent alone in reducing exacerbations, as well as improving lung function and health status. ${ }^{1}$

Recent post hoc analyses of published trials have examined the early response to ICS-LABA combination 


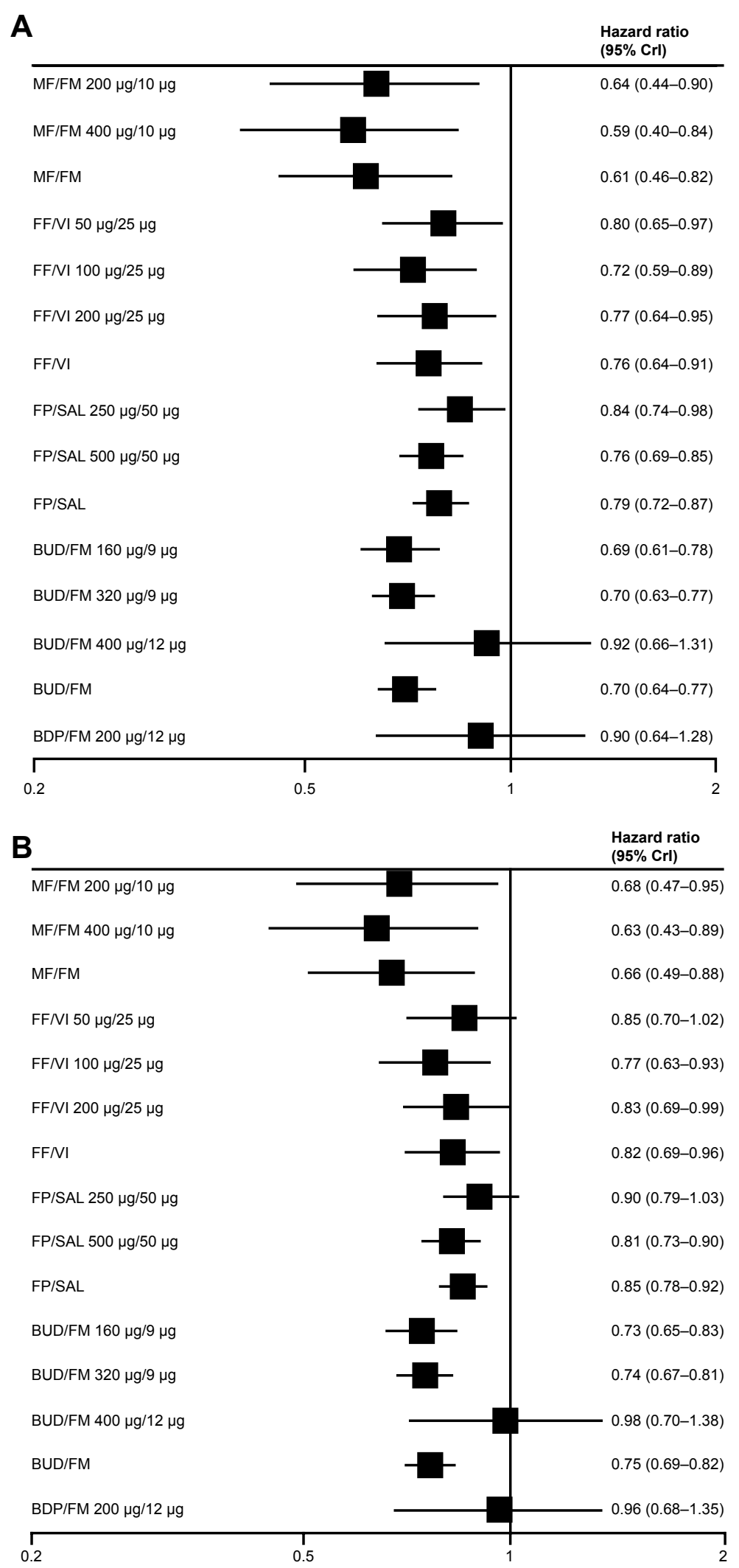

Figure I Effectiveness of ICS-LABA inhalers.

Notes: Pooled effect estimates of combined ICS-LABA inhalers vs (A) placebo and (B) LABA on moderate-severe exacerbations. Copyright @2014. Dove Medical Press. Reproduced with permission from Oba $Y$ and Lone NA. Comparative efficacy of inhaled corticosteroid and long-acting beta agonist combinations in preventing COPD exacerbations: a Bayesian network meta-analysis. Int J Chron Obstruct Pulmon Dis. 2014;9:469-479.30

Abbreviations: BDP, beclomethasone dipropionate; BUD, budesonide; Crl, credibility interval; FF, fluticasone furoate; FM, formoterol; FP, fluticasone propionate; ICS, inhaled corticosteroid; LABA, long-acting $\beta_{2}$-agonist; MF, mometasone furoate; SAL, salmeterol; VI, vilanterol. 
therapy. ${ }^{32,33}$ Lower exacerbation rates and improved lung function $\left(\mathrm{FEV}_{1}\right.$ and $\left.\mathrm{PEF}\right)$ were evident as early as 3 months after starting treatment with budesonide-formoterol vs placebo. Early improvements in $\mathrm{FEV}_{1}$ and total score on the SGRQ were associated with future response, and early $\mathrm{FEV}_{1}$ improvements (but not SGRQ-score improvements) predicted lower risk of future COPD exacerbations.

Long-acting muscarinic antagonists (LAMAs), such as tiotropium, have a prolonged bronchodilator effect that has been shown to reduce exacerbations to a greater degree than LABA monotherapy. ${ }^{1,34,35}$ Despite being the most commonly prescribed first-line treatments, few clinical studies have compared LAMA monotherapy to ICS-LABA combination therapy. ${ }^{36}$ Using a large administrative claims database in the US, the real-world effectiveness of tiotropium was compared to budesonide-formoterol. The ICS-LABA combination reduced the risk of COPD exacerbation by $22 \%$ compared with LAMA monotherapy; however, the results could have been skewed by a high number of patients having possible comorbid asthma. The Investigating New Standards for Prophylaxis in Reducing Exacerbations (INSPIRE) study compared the efficacy of salmeterol-fluticasone with tiotropium monotherapy in preventing exacerbations in patients with severe and very severe COPD. ${ }^{37}$ The exacerbation rate was not significantly different between the groups treated with ICS-LABA therapy and LAMA monotherapy, but the ICS-LABA group had better health status and was less likely to withdraw. The fact that LABAs and LAMAs work on different receptors to induce bronchodilation provides a rationale for their use in combination to optimize bronchodilation. ${ }^{38}$ The comparative efficacy of LAMALABA (dual bronchodilators) vs ICS-LABA therapy in reducing exacerbations is currently a matter of keen interest. The Effect of Indacaterol Glycopyrronium vs Fluticasone Salmeterol on COPD Exacerbations (FLAME) study compared the efficacy of a LAMA-LABA combination (glycopyrronium $50 \mu \mathrm{g}$-indacaterol $110 \mu \mathrm{g}$ ) with ICS-LABA (fluticasone $500 \mu \mathrm{g}$-salmeterol $50 \mu \mathrm{g}$ ) therapy in reducing exacerbation risk for patients with COPD ${ }^{39}$ For patients with a history of exacerbation in the previous year, the annual rate of moderate or severe exacerbation was significantly lower for the LAMA-LABA group (0.98) than for the ICS-LABA group $(1.19, P<0.001)$.

\section{Predictors of response}

Post hoc analyses suggest eosinophil counts in blood and sputum may be used as predictive biomarkers for the efficacy of ICSs in reducing exacerbations. ${ }^{40-43}$ Dose-response effectiveness of ICSs has been demonstrated in patients with elevated eosinophils,${ }^{44}$ and eosinophil levels may be able to direct treatment during COPD exacerbations. Eosinophilic inflammation in COPD, defined as sputum eosinophils $\geq 3 \%$, has been reported in up to $28 \%$ of cases during an acute exacerbation and up to $38 \%$ of patients with stable disease. ${ }^{44}$ However, measurement of sputum eosinophils is unsuitable for point-of-care testing and requires experience to differentiate inflammatory cell counts. Measurement of blood eosinophils may be a more useful biomarker for routine practice. The threshold for eosinophilic inflammation continues to be debated, with some reports suggesting a threshold of $>2 \%, 3 \%$, or $4 \%$ of the total white-blood-cell count, whereas others propose a total eosinophil count of 150, 220, or 300 cells $/ \mu \mathrm{L} .{ }^{45,46}$

The INCONTROL study showed that for patients with blood-eosinophil counts $\geq 100$ cells $/ \mu \mathrm{L}$, exacerbations were reduced significantly more with budesonide-formoterol compared with formoterol alone $(P=0.015) .{ }^{42}$ The higher the blood-eosinophil count, the greater the exacerbation rate without ICSs and the greater the reduction in exacerbations with ICSs, which tends to reach a plateau around eosinophil counts of 400 cells $/ \mu \mathrm{L}$. The impact of blood-eosinophil count on response to ICSs was also found to be greater as the eosinophil count increased by Pascoe et al in their analysis of data from two parallel randomized controlled trials on the addition of fluticasone furoate to vilanterol. ${ }^{47}$

Disparate findings for blood eosinophils were reported in the Subpopulations and Intermediate Outcome Measures in COPD (SPIROMICS) cohort, in which blood eosinophils alone were not a reliable predictor of COPD exacerbations in contrast to sputum eosinophils, and the association between blood and sputum eosinophils was weak. ${ }^{48}$ Differences in study populations could account for the disparate findings, as the INCONTROL study had a larger number of smokers with more exacerbations compared with the SPIROMICS cohort. ${ }^{42,48}$

Elevated eosinophil counts in the blood and airway walls are also observed in patients with COPD who have other signs of inflammation. ${ }^{49}$ Tamada et al evaluated 331 COPD patients for asthma-like airway inflammation or atopic factors using fractional exhaled nitric oxide and serum IgE, respectively. ${ }^{50}$ High fractional exhaled nitric oxide ( $\geq 35$ parts per billion) was present in $16 \%$ of patients, high $\operatorname{IgE}(\geq 173 \mathrm{IU} / \mathrm{mL})$ occurred in $36 \%$ of patients, and both factors were present in $8 \%$ of patients. Furthermore, there is another type of COPD that occurs with asthma, termed 
asthma-COPD overlap (ACO). A clear definition of ACO has yet to be determined, ${ }^{50,51}$ but a systematic review and meta-analysis of 17 studies including COPD and asthma used a definition of any COPD patient with at least one of the following asthma characteristics: diagnosis of asthma, $\mathrm{FEV}_{1}$ reversibility $\geq 12 \%$ and $\geq 200 \mathrm{~mL}$ of change from baseline, PEF variability $\geq 20 \%$, and airway hyperresponsiveness to methacholine or histamine. ${ }^{51}$ Across the 17 studies, the pooled prevalence of ACO was $27 \%$ and $28 \%$ in population- and hospital-based studies, respectively. In five studies, ACO was associated with worse outcomes, including more frequent exacerbations, hospitalizations, and emergency-department visits, and two studies reported significantly higher use of ICS-LABA combinations in patients with ACO than those with COPD. Objective measures of airway inflammation and/or atopy (eg, IgE levels) indicate a smaller proportion of patients with ACO defined by symptoms, lung function, or physician diagnosis; however, these measures may be important for identifying patients who would benefit from ICS-LABA therapy. ${ }^{1}$ The presence of eosinophilic inflammation has not been studied extensively in this population.

\section{Effect of smoking status on ICS response}

Despite a causal link between cigarette smoking and COPD, a substantial percentage of patients with moderate-severe COPD continue to smoke $(30 \%-43 \%) .{ }^{52}$ Sustained smoking cessation reduces the rate of decline in $\mathrm{FEV}_{1}$ and decreases respiratory symptoms among smokers with early COPD. ${ }^{53}$ However, reductions in the amount of smoking up to $50 \%$ have no observable effect on the decline in $\mathrm{FEV}_{1}$, suggesting that total or near-total abstinence from smoking is required to reduce the effect of cigarette smoke on lung function. ${ }^{53}$

The adverse effects of smoking in patients with COPD or asthma have been attributed to increased airway inflammation and reduced CS responsiveness, ${ }^{54}$ but the majority of studies examining the effect of smoking on CS responsiveness have been conducted in patients with asthma. ${ }^{55}$ Although it has been proposed that the oxidative and nitrative stress associated with cigarette smoking may inactivate HDAC2 in COPD patients and contribute to ICS resistance, ${ }^{17}$ studies of smokers and ex-smokers generally have failed to identify a significant difference of ICSs on clinical and inflammatory parameters, including HDAC2.$^{55,56}$ Reductions in bronchial mast cells have been observed with both short- and longterm ICS treatment in smokers and ex-smokers with COPD, whereas reductions in $\mathrm{CD}^{+}, \mathrm{CD}^{+}$, and $\mathrm{CD}^{+}$cells were observed with short-term ICSs in current smokers only. ${ }^{55}$
These differential effects of ICSs on specific cell types may be related to epigenetic regulation occurring with DNA methylation and histone modification. ${ }^{55}$ In a comparison of ICS therapy in smokers and ex-smokers with COPD, IL8 and neutrophil-related elastase activity increased in smokers and were unchanged or decreased in ex-smokers. ${ }^{57}$ Sputum eosinophils may be reduced in smokers as a result of the nitric oxide and carbon monoxide present in cigarette smoke. ${ }^{54} \mathrm{~A}$ recent post hoc analysis of budesonide-formoterol studies in patients with COPD (INCONTROL) found that among current smokers, a greater reduction in exacerbation rate was observed with ICS-LABA therapy vs LABA alone at higher peripheral blood-eosinophil counts. ${ }^{42}$ These cell- and tissuespecific responses may be related to the heterogeneous nature of COPD, and suggest that reduced steroid responsiveness is not a general characteristic of the disease. ${ }^{42,55}$ These findings highlight the need for further evaluation of appropriate biomarkers of disease severity and treatment selection and their relationship to smoking status.

\section{Safety considerations}

A review of long-term studies of ICS monotherapy in patients with COPD revealed important information about their safety (Table 1). Skin bruising and oral candidiasis were increased with ICS therapy in most studies. ${ }^{7,8,10,43,58}$ In a subset of patients from the Lung Health Study, no effect of ICSs on adrenal function was observed over the 3-year study duration. ${ }^{59}$ These pivotal long-term studies of ICS monotherapy in COPD patients did not identify a difference in occurrence of cataracts compared with placebo. ${ }^{7,8,10}$ However, an increased risk of cataracts was observed in a populationbased, cross-sectional study of more than 3,000 patients, in which ICS use was associated with significantly increased prevalence of nuclear and posterior subcapsular cataracts, and higher cumulative lifetime doses were associated with higher risks. ${ }^{60}$ In a follow-up analysis 10 years later, the risk of incident cataracts was significant only for patients who had ever used both ICSs and oral CSs. ${ }^{61}$ Moreover, using a large electronic medical record database in the UK, ICSs or ICS-LABA (fluticasone propionate-salmeterol) combination therapy was not associated with increased risks of cataracts or glaucoma. ${ }^{62}$ The 1-year Efficacy and Tolerability of Budesonide/Formoterol in One Hydrofluoroalkane Pressurized Metered-Dose Inhaler in Patients with Chronic Obstructive Pulmonary Disease (SUN) study of budesonide-formoterol in COPD patients identified numerically more frequent adverse events typically associated with ICSs, including oral candidiasis, ocular effects, skin effects, and bone effects, 
in the ICS-LABA group than the LABA-alone or placebo groups. ${ }^{63}$ However, there were no differences in objectively measured changes in lenticular opacity or intraocular pressure, nor clinically relevant changes in bone-mineral density (BMD), across the three treatment groups.

Osteoporosis is a systemic feature of COPD, with prevalence that is two to five times higher than that in age-matched subjects without airflow obstruction. ${ }^{64}$ In a cross-sectional study of COPD patients, the dosage or duration of ICSs or oral CSs used was not different between those with osteoporosis and those with normal bone mass. ${ }^{64}$ Over the 3 -year TORCH study, changes in BMD at the hip and lumbar spine were small, and there were no significant differences between any of the active treatment groups (ICS-LABA, ICS alone, LABA alone) and placebo. ${ }^{65}$ Long-term studies analyzed in the Cochrane database review did not show any major effect of ICS therapy on fractures or BMD over 3 years. ${ }^{16}$ In contrast, a meta-analysis of 16 randomized controlled trials (of which 14 evaluated fluticasone and two budesonide) showed an increased risk of fractures $(>20 \%)$ with more than 24 weeks of ICS therapy vs control. ${ }^{66}$ Significant reduction in BMD at the lumbar spine $(1.33 \%, P=0.007)$ and femoral neck $(1.78 \%$, $P<0.001)$ was observed with triamcinolone in the Lung Health Study, ${ }^{7,67}$ but not with budesonide in the European Respiratory Society study (a small but significant decline in femoral trochanter BMD was observed with placebo vs budesonide, $P=0.02) .{ }^{8}$ Current recommendations suggest measuring BMD in patients with COPD intermittently to assess fracture risk and treating those with significantly reduced BMD. ${ }^{68}$

\section{Effect of ICSs on pneumonia risk in patients with COPD}

The risk of pneumonia is increased in patients with COPD and further increased in those with a history of exacerbations and more severe disease. ${ }^{69,70}$ ICS-containing therapy for COPD has generally been associated with an increased risk of nonfatal pneumonia. ${ }^{70}$ A 2009 meta-analysis of 18 studies of ICS therapy in COPD estimated an approximately $60 \%$ increased risk of pneumonia without a significant increase in pneumonia-related death or overall mortality. ${ }^{71}$ In a newuser cohort study using a medical record database, ICS use was associated with a $49 \%$ increased risk of pneumonia (vs long-acting bronchodilator) that was attenuated to $19 \%$ with at least 6 months of exposure. ${ }^{70}$

Differences in study design and duration, population studied, and definition of pneumonia events may contribute to variability in pneumonia rates across studies. ${ }^{69,70}$ Pneumonia risk may also differ by the specific ICS used. In the
2009 meta-analysis, two of 18 trials evaluated budesonide at $800 \mu \mathrm{g} /$ day, and 16 of 18 trials evaluated fluticasone propionate at dosages of $1,000 \mu \mathrm{g} /$ day $(\mathrm{N}=10)$ or $250 \mu \mathrm{g} /$ day $(\mathrm{N}=6)$. In a separate meta-analysis of seven large budesonide studies in COPD, no significant increased risk of pneumonia was determined with budesonide vs control of either placebo or formoterol (overall risk 1.05, 95\% CI 0.81-1.37). ${ }^{72}$ The Investigation of the Past 10 Years Health Care for Primary Care Patients With Chronic Obstructive Pulmonary Disease (PATHOS) study investigated the incidence of pneumonia in patients with COPD using data from national Swedish health registries, comparing propensity-matched populations treated with budesonide-formoterol $(\mathrm{N}=2,734)$ and fluticasone-salmeterol $(\mathrm{N}=2,734) .{ }^{73}$ Patients in the fluticasonesalmeterol group experienced an approximately $75 \%$ greater occurrence of pneumonia, including pneumonia requiring hospitalization, compared with the budesonide-formoterol group $(P<0.001)$. Additionally, among patients using ICSs at baseline and followed for 4 years in the Understanding Potential Long-Term Impacts on Function with Tiotropium (UPLIFT) study, the risk of pneumonia was increased by $>20 \%$ compared with those who did not use ICSs, but this increased risk was noted only in patients receiving fluticasone propionate and not in those using other ICSs (Table 2). ${ }^{74}$ Fluticasone was also associated with a higher risk of any pneumonia, but not serious pneumonia, compared with budesonide in a Cochrane database review of 43 randomized controlled trials (26 fluticasone studies and 17 budesonide studies). ${ }^{75}$ Differences in outcome between ICSs and placebo may be due to uneven distribution of baseline characteristics because patients with more severe disease received more intensive treatment; however, patient subgroups based on the ICS they received were well matched, such that baseline characteristics cannot explain differences between fluticasone and other ICSs. ${ }^{74}$ Fluticasone differs structurally from beclomethasone and budesonide because it has a fluorine moiety, which leads to distribution in the lipid membranes and slower clearance from lungs and other tissue, which may impact lung immunity and inflammatory responses. ${ }^{74,76}$ This study also suggested that the use of LAMA therapy may ameliorate some of the respiratory adverse effects of ICSs, supporting their use in combination. ${ }^{74}$ The absolute risk of pneumonia is low, ${ }^{77}$ and the authors' experience suggests that few physicians or patients avoid ICS therapy as a result of this risk. In summary, the physician and patient must consider the benefit of ICSs in reducing the future risk of exacerbations in relation to the increased pneumonia risk of ICS-containing therapy. ${ }^{70,72}$ 
Table 2 Distribution of pneumonia events and incidence rates by treatment in the UPLIFT study

\begin{tabular}{|c|c|c|c|c|c|}
\hline Treatment & Events & Years in study & Incidence rate & $\begin{array}{l}\text { Incidence-rate } \\
\text { ratio }(95 \% \mathrm{Cl})\end{array}$ & $P$-value \\
\hline \multicolumn{6}{|c|}{ Any ICS vs no ICS } \\
\hline No ICS & 383 & 6,885 & 0.056 & & Reference \\
\hline ICS & 738 & 10,836 & 0.068 & $1.22(1.08-1.38)$ & 0.012 \\
\hline \multicolumn{6}{|c|}{ FP vs other ICS and no ICS } \\
\hline FP & 437 & 5,685 & 0.077 & $1.38(1.20-1.58)$ & $<0.001$ \\
\hline Other ICS & 301 & $5,|5|$ & 0.058 & 1.05 & 0.52 \\
\hline No ICS & 383 & 6,885 & 0.056 & & Reference \\
\hline \multicolumn{6}{|c|}{ Effect of Tio on pneumonia rate, irrespective of ICS } \\
\hline FP/Pbo & 230 & 2,720 & 0.081 & $1.45(1.19-1.77)$ & $<0.001$ \\
\hline FP/Tio & 217 & 2,964 & 0.073 & $1.31(1.08-1.60)$ & 0.006 \\
\hline Other ICS/Pbo & 153 & 2,461 & 0.062 & $1.12(0.90-1.38)$ & 0.29 \\
\hline Other ICS/Tio & 148 & 2,690 & 0.055 & $0.99(0.79-1.23)$ & 0.94 \\
\hline No ICS/Pbo & 184 & 3,317 & 0.055 & & Reference \\
\hline No ICS/Tio & 199 & 3,567 & 0.056 & $1.00(0.82-1.22)$ & 0.95 \\
\hline
\end{tabular}

Note: Reproduced with permission from Morjaria JB, Rigby A, Morice AH. Inhaled corticosteroid use and the risk of pneumonia and COPD exacerbations in the UPLIFT study. Lung. 20I7;195(3):28I-288. Creative Commons license and disclaimer available from: http://creativecommons.org/licenses/by/4.0/legalcode. ${ }^{74}$

Abbreviations: FP, fluticasone propionate; ICS, inhaled corticosteroid; Pbo, placebo; Tio, tiotropium.

\section{Role of ICSs in current COPD treatment}

Large clinical trials and systematic reviews/meta-analyses of clinical trial data provide evidence for the development of COPD-treatment guidelines. ${ }^{1}$ Currently, GOLD guidelines provide recommendations for drug selection based on a patient's symptom intensity and disease severity assessed by prior and future risk of exacerbations. ${ }^{1,45}$ ICS-LABA combinations have been shown to reduce exacerbations, improve lung function, and improve health status. ${ }^{14,26,28-30}$ ICS-LABA combinations are thus recommended as a treatment option for COPD patients with a history of frequent exacerbations, ${ }^{1}$ but they are commonly prescribed as first-line treatments, regardless of COPD severity. ${ }^{38,74}$ Over the past 5 years, there has been an increase in new drugs and delivery devices, adding to the complexity of COPD treatment options.$^{45}$ However, the data reviewed herein provide information to identify patient groups that may benefit from ICS use (Figure 2). Concerns with ICS use are related to the safety considerations described in the previous section and the potential risks associated with withdrawal of ICS therapy. ${ }^{45,74,78}$ Long-term adverse events described in some studies are complicated by concomitant oral CS use and confounding disease severity, as well as comorbidities. It is important that exacerbations be differentiated from other events that may be related to common comorbidities of COPD, including acute coronary syndrome, worsening congestive heart failure, pulmonary embolism, and pneumonia. ${ }^{1}$ Although for many years it was believed that stopping ICS use could trigger an exacerbation, it has recently been shown that withdrawal of ICSs is possible, particularly when other medications are introduced concomitantly. ${ }^{45}$ In the Withdrawal of Inhaled Steroids during Optimized
Bronchodilator Management (WISDOM) study, ICS therapy was withdrawn gradually over 12 weeks from a triple combination, without an overall increased risk of exacerbations compared with the group that remained on triple therapy (HR $1.06,95 \%$ CI 0.94-1.19). ${ }^{79}$ However, in the group in which ICS therapy was withdrawn, $\mathrm{FEV}_{1}$ declined and health status tended to worsen significantly, albeit modestly, compared with patients who remained on ICS therapy. Moreover, in a subset of the overall patient population $(\sim 20 \%)$ with eosinophil counts $\geq 4 \%$ or $\geq 300$ cells $/ \mu \mathrm{L}$, withdrawal of ICSs was associated with an increased risk of exacerbations. ${ }^{46}$ Still, for patients who are at low risk of exacerbation (ie, $\mathrm{FEV}_{1}>50 \%$ predicted, fewer than two exacerbations/year), ICSs can be withdrawn safely as long as maintenance LABA therapy is continued. ${ }^{80}$

\section{Future directions: triple therapy and beyond}

The step up to triple therapy with ICS + LABA + LAMA may improve lung function and patient-reported outcomes for COPD patients (eg, the addition of LAMA to ICSLABA reduces exacerbation risk). ${ }^{1}$ In the Single Inhaler Triple Therapy vs Inhaled Corticosteroid Plus Long-acting $\beta_{2}$-Agonist Therapy for Chronic Obstructive Pulmonary Disease (TRILOGY) study of COPD patients with severe or very severe airflow limitation (ie, $\mathrm{FEV}_{1}<50 \%$ predicted and at least one moderate or severe exacerbation in the previous 12 months), triple therapy (beclomethasone dipropionateformoterol fumarate-glycopyrronium bromide) in a single inhaler significantly improved predose and postdose $\mathrm{FEV}_{1}$ and SGRQ total score and also reduced the exacerbation rate by $23 \%$ compared with beclomethasone dipropionate-formoterol 


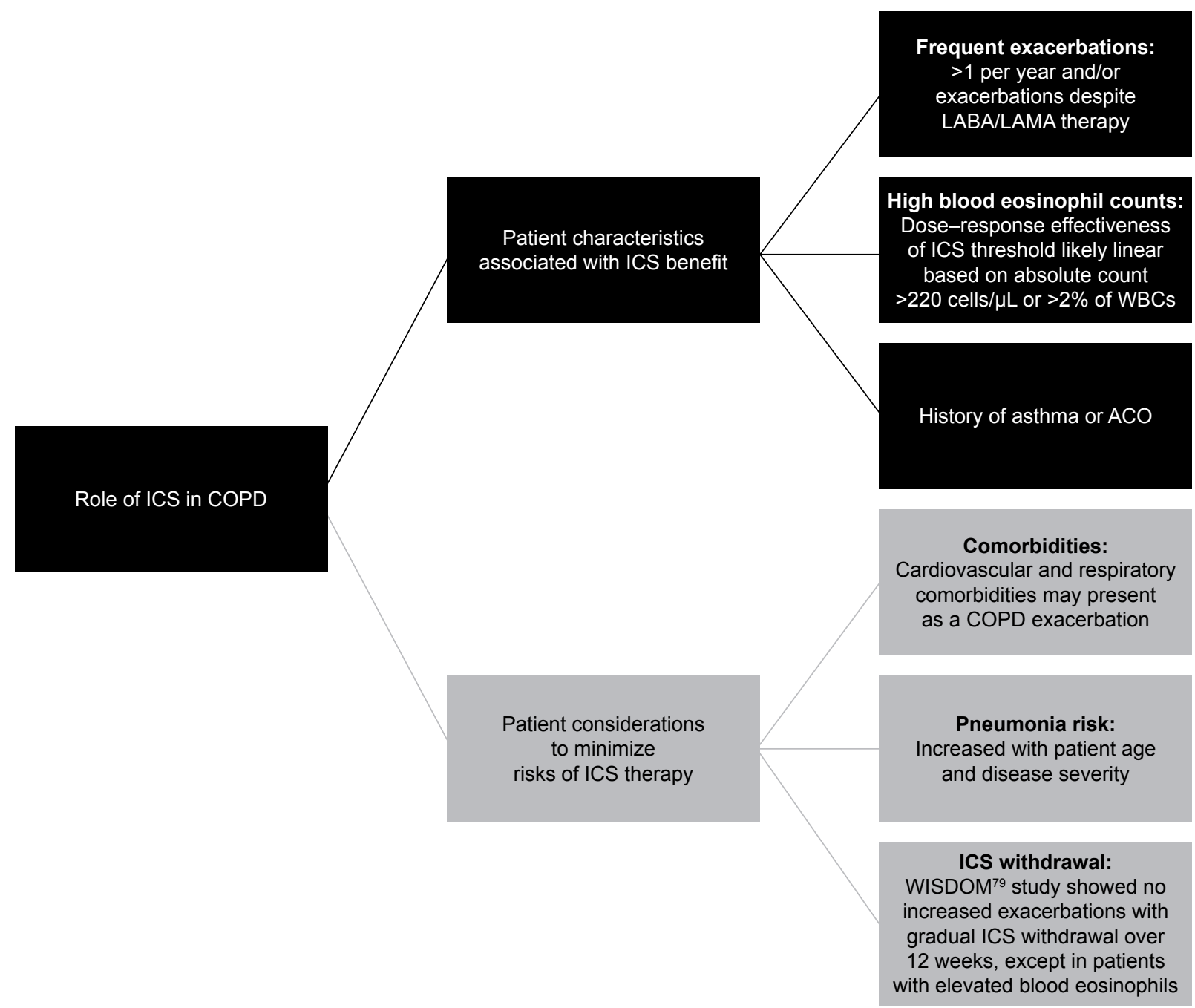

Figure 2 The role of ICS in patients with COPD.

Notes: Eosinophil thresholds for beneficial ICS effect are discussed in the text. Data regarding the effect of ICS on comorbidity presence or course are limited.

Abbreviations: ACO, asthma-COPD overlap; ICS, inhaled corticosteroid; LABA, long-acting $\beta_{2}$-agonist; LAMA, long-acting muscarinic antagonist; WBCs, white blood cells.

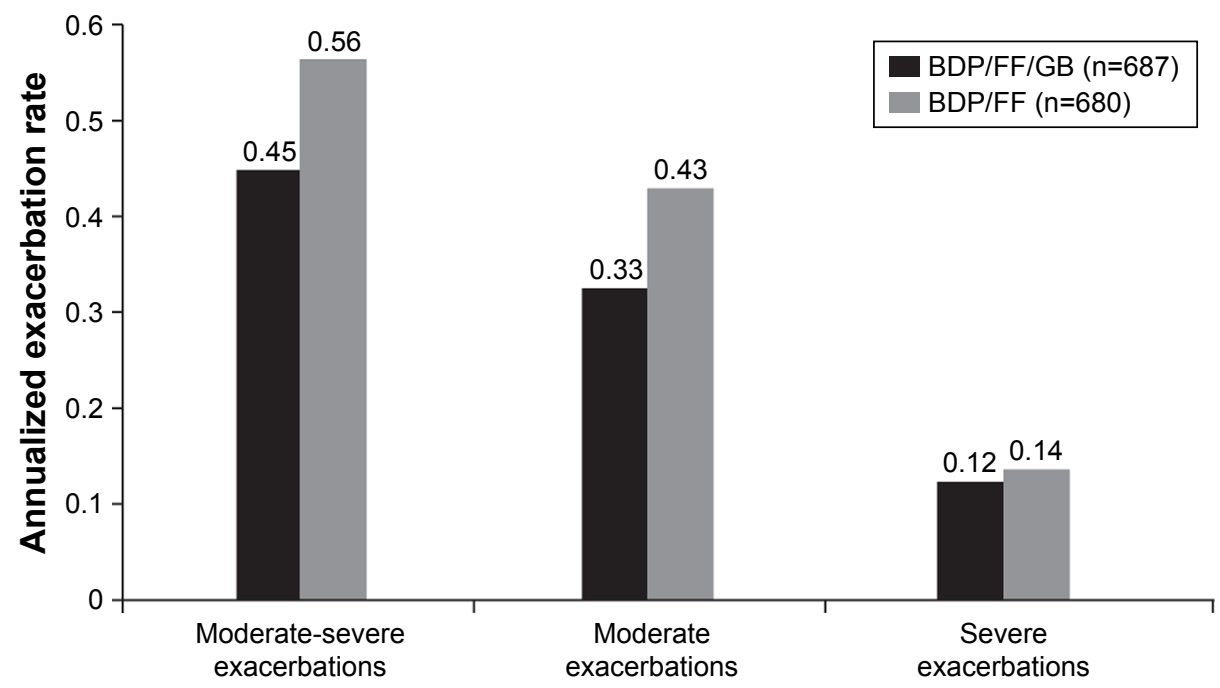

Figure 3 COPD exacerbations in the TRILOGY study.

Notes: Unadjusted annual rate of COPD exacerbations of differing severity in the intent-to-treat population for the TRILOGY study. Reprinted from The Lancet, 388(I0048), Singh D, Papi A, Corradi M, et al. Single inhaler triple therapy versus inhaled corticosteroid plus long-acting $\beta 2$-agonist therapy for chronic obstructive pulmonary disease (TRILOGY): a double-blind, parallel group, randomised controlled trial, Pages 963-973, Copyright 2016, with permission from Elsevier. ${ }^{81}$

Abbreviations: BDP, beclomethasone dipropionate; FF, fluticasone furoate; GB, glycopyrronium bromide. 
fumarate (Figure 3). ${ }^{81}$ Patients enrolled in this study could have been receiving ICS-LABA, ICS-LAMA, or LABA-LAMA combination therapy or LAMA monotherapy and entered a 2-week run-in phase in which they received ICS-LABA prior to randomization. As such, escalation from LABA-LAMA therapy directly to triple therapy needs to be evaluated. The recently published Lung Function and Quality of Life Assessment in COPD with Closed Triple Therapy (FULFIL) study results support a benefit of single-inhaler triple therapy compared with ICS-LABA for lung function, health status, and exacerbation rate at 24 weeks. ${ }^{82}$ Moreover, results of the Informing the Pathway of COPD Treatment (IMPACT) study demonstrated that the triple combination of fluticasone furoate-umeclidinium-vilanterol reduced the rate of moderate or severe exacerbations more effectively than both the ICS-LABA (fluticasone furoate-vilanterol, 15\% difference, $P<0.001$ ) and the LABA-LAMA (umeclidinium-vilanterol, $25 \%$ difference, $P<0.001)$ combinations. ${ }^{83}$ Interestingly, these results imply that ICS-LABA might be superior to LABALAMA in reducing exacerbations in this $>10,000$-patient study, in direct contrast to the findings from the FLAME study. ${ }^{39}$ A number of factors may have contributed to the disparate findings in the IMPACT and FLAME studies, including different patient populations, study-design differences for the run-in period and ICS withdrawal, and different methods of statistical analyses of end points. More data are needed to determine appropriate patient selection criteria for ICS-LABA, LABA-LAMA, and triple-therapy regimens.

In contrast to these positive results for triple therapy, a 2015 systematic review and meta-analysis of seven trials of triple therapy using tiotropium and an ICS-LABA fixed-dose combination in a separate inhaler vs tiotropium monotherapy showed no significant benefit for triple therapy on mortality or exacerbations. ${ }^{84}$ Improvement in $\mathrm{FEV}_{1}$ and SGRQ score was greater with triple therapy, but lower than the minimal clinically important difference. Six of the seven trials were $\leq 24$ weeks in duration. These findings highlight potential differences in triple-therapy regimens, the need for studies of longer duration, and the impact of single inhalers (presumably as a result of increased adherence) compared with multiple inhalers. Indeed, the use of multiple inhalers adds complexity to the treatment regimen, especially when considering the different types of inhalers currently available and patient preferences. ${ }^{85}$

An analysis of prescribing patterns in the UK indicated that $32 \%$ of patients received triple therapy between 2002 and 2010, regardless of GOLD severity category. ${ }^{86}$ Few patients in GOLD groups A, B, C, or D (as defined in the 2011 GOLD report) received triple therapy prior to or at initial diagnosis, but after initial diagnosis, prescriptions for triple therapy occurred in $19 \%, 28 \%, 37 \%$, and $46 \%$ of patients in GOLD groups $\mathrm{A}, \mathrm{B}, \mathrm{C}$, and $\mathrm{D}$, respectively. ${ }^{86}$ The most frequent treatment-escalation pathway was from ICS-LABA to triple therapy. Therefore, the majority of COPD patients may be overtreated compared with GOLD guidelines, with $75 \%$ of those receiving triple therapy having only mild or moderate COPD.$^{87,88}$ However, it is important to note that there have been no studies to evaluate the use of aggressive treatment to reduce COPD exacerbations followed by de-escalation of the therapy. Triple therapy may allow the assumption that a patient is receiving optimal treatment for COPD with optimal bronchodilation via two mechanisms plus anti-inflammatory effects. ${ }^{86}$ In addition, triple therapy does not appear to be associated with a greater risk of adverse events compared with ICS-LABA or LAMA monotherapy. ${ }^{81,84}$

Fluticasone furoate-umeclidinium-vilanterol inhalation powder (Trelegy Ellipta; GlaxoSmithKline, Research Triangle Park, NC, USA) was recently approved by the FDA as the first once-daily single-inhaler triple therapy for COPD. ${ }^{89}$ Combination triple therapy in a single inhaler may increase the likelihood of better adherence, ${ }^{85}$ but it also increases the expense of the product in the absence of generic equivalents. ${ }^{45}$ National Institute for Health and Care Excellence guidelines state that triple therapy is cost-effective only in patients who have $\mathrm{FEV}_{1}<50 \%$ predicted and frequent exacerbations (two or more in past 12 months). ${ }^{86,90}$ In this regard, it is interesting that only $2.1 \%$ of patients in the SPIROMICS cohort, of whom $30 \%$ had severe airflow obstruction, had two or more exacerbations in each year over a 3 -year period..$^{91}$ Therefore, the frequent exacerbator phenotype appears to be much less common than reported in the Evaluation of COPD Longitudinally to Identify Predictive Surrogate End-points (ECLIPSE) study. ${ }^{92}$ Accurate assessment of exacerbation history and future risk is thus necessary to guide individualized therapy decisions in patients with COPD.

For patients with COPD who continue to experience exacerbations while receiving LABA-LAMA-ICS therapy, the addition of a phosphodiesterase 4 inhibitor or macrolide antibiotic has been recommended. ${ }^{1}$ Moreover, therapeutic agents targeting eosinophils, namely anti-IL5 and antiIL5-receptor monoclonal antibodies, have been evaluated to reduce the risk of exacerbations in COPD patients with high eosinophil counts and a history of exacerbations despite optimized standard-of-care therapy ${ }^{43}$ however, results have been inconsistent. ${ }^{93-95}$

Overall, the use of ICSs in dual and triple therapy for COPD has been shown to reduce exacerbations and improve 
symptoms. Furthermore, individualizing therapies based on each patient's phenotype, including risk factors and comorbidities, has the potential to maximize the benefit:risk ratio of COPD treatment.

\section{Acknowledgments}

Medical writing support was provided by Katie Gersh, PhD of MedErgy (Yardley, PA, USA), in accordance with Good Publication Practice (GPP3) guidelines and funded by AstraZeneca (Wilmington, DE, USA). AstraZeneca reviewed the manuscript for medical accuracy.

\section{Disclosure}

DPT has served on advisory boards for AstraZeneca, Novartis, and Sunovion; as a speaker for Boehringer Ingelheim, AstraZeneca, and Sunovion; and as a consultant for Theravance/Innoviva. CS has current, past, or pending grants in COPD from Adverum, the Alpha-1 Foundation, BTG, CSL Behring, Grifols, MatRx, NIH, Novartis, PneumRx, and Shire. He consults for Abeona, AstraZeneca, CSA Medical, CSL Behring, GlaxoSmithKline, Grifols, and Uptake Medical on COPD. The authors report no other conflicts of interest in this work.

\section{References}

1. Global Initiative for Chronic Obstructive Lung Disease. Global Strategy for the Diagnosis, Management, and Prevention of COPD. Bethesda(MD): GOLD; 2018.

2. Saetta M, Finkelstein R, Cosio MG. Morphological and cellular basis for airflow limitation in smokers. Eur Respir J. 1994;7(8):1505-1515.

3. Finkelstein R, Fraser RS, Ghezzo H, Cosio MG. Alveolar inflammation and its relation to emphysema in smokers. Am J Respir Crit Care Med. 1995;152(5 Pt 1):1666-1672.

4. Thompson AB, Mueller MB, Heires AJ, et al. Aerosolized beclomethasone in chronic bronchitis: improved pulmonary function and diminished airway inflammation. Am Rev Respir Dis. 1992;146(2):389-395.

5. Confalonieri M, Mainardi E, della Porta R, et al. Inhaled corticosteroids reduce neutrophilic bronchial inflammation in patients with chronic obstructive pulmonary disease. Thorax. 1998;53(7):583-585.

6. Paggiaro PL, Dahle R, Bakran I, Frith L, Hollingworth K, Efthimiou J. Multicentre randomised placebo-controlled trial of inhaled fluticasone propionate in patients with chronic obstructive pulmonary disease. Lancet. 1998;351(9105):773-780.

7. Wise R, Connett J, Weinmann G, Scanlon P, Skeans M. Effect of inhaled triamcinolone on the decline in pulmonary function in chronic obstructive pulmonary disease. $N$ Engl J Med. 2000;343(26):1902-1909.

8. Pauwels RA, Löfdahl C-G, Laitinen LA, et al. Long-term treatment with inhaled budesonide in persons with mild chronic obstructive pulmonary disease who continue smoking. N Engl J Med. 1999;340(25):1948-1953.

9. Vestbo J, Sørensen T, Lange P, Brix A, Torre P, Viskum K. Long-term effect of inhaled budesonide in mild and moderate chronic obstructive pulmonary disease: a randomised controlled trial. Lancet. 1999; 353(9167):1819-1823.

10. Burge PS, Calverley PM, Jones PW, Spencer S, Anderson JA, Maslen TK. Randomised, double blind, placebo controlled study of fluticasone propionate in patients with moderate to severe chronic obstructive pulmonary disease: the ISOLDE trial. BMJ. 2000;320(7245):1297-1303.
11. Highland KB, Strange C, Heffner JE. Long-term effects of inhaled corticosteroids on FEV1 in patients with chronic obstructive pulmonary disease: a meta-analysis. Ann Intern Med. 2003;138(12):969-973.

12. Soriano JB, Sin DD, Zhang X, et al. A pooled analysis of $\mathrm{FEV}_{1}$ decline in COPD patients randomized to inhaled corticosteroids or placebo. Chest. 2007;131(3):682-689.

13. Anthonisen NR, Connett JE, Kiley JP, et al. Effects of smoking intervention and the use of an inhaled anticholinergic bronchodilator on the rate of decline of $\mathrm{FEV}_{1}$ : the Lung Health Study. JAMA. 1994;272(19): $1497-1505$.

14. Sin DD, McAlister FA, Man SF, Anthonisen NR. Contemporary management of chronic obstructive pulmonary disease: scientific review. JAMA. 2003;290(17):2301-2312.

15. Agarwal R, Aggarwal AN, Gupta D, Jindal SK. Inhaled corticosteroids vs placebo for preventing COPD exacerbations: a systematic review and metaregression of randomized controlled trials. Chest. 2010;137(2):318-325.

16. Yang IA, Clarke MS, Sim EH, Fong KM. Inhaled corticosteroids for stable chronic obstructive pulmonary disease. Cochrane Database Syst Rev. 2012;7:CD002991.

17. Barnes PJ, Shapiro SD, Pauwels RA. Chronic obstructive pulmonary disease: molecular and cellular mechanisms. Eur Respir J. 2003;22(4): 672-688.

18. Barnes PJ. Immunology of asthma and chronic obstructive pulmonary disease. Nat Rev Immunol. 2008;8(3):183-192.

19. Cheng SL, Su KC, Wang HC, Perng DW, Yang PC. Chronic obstructive pulmonary disease treated with inhaled medium- or high-dose corticosteroids: a prospective and randomized study focusing on clinical efficacy and the risk of pneumonia. Drug Des Devel Ther. 2014;8:601-607.

20. Boardman C, Chachi L, Gavrila A, et al. Mechanisms of glucocorticoid action and insensitivity in airways disease. Pulm Pharmacol Ther. 2014;29(2):129-143.

21. Powell H, Gibson PG. High dose versus low dose inhaled corticosteroid as initial starting dose for asthma in adults and children. Cochrane Database Syst Rev. 2004;2(2):CD004109.

22. US Food and Drug Administration. Chronic obstructive pulmonary disease: developing drugs for treatment. 2016. Available from: https://www.gpo.gov/fdsys/pkg/FR-2016-05-20/pdf/2016-11855.pdf. Accessed July 12, 2018.

23. Usmani OS, Ito K, Maneechotesuwan K, et al. Glucocorticoid receptor nuclear translocation in airway cells after inhaled combination therapy. Am J Respir Crit Care Med. 2005;172(6):704-712.

24. Haque R, Hakim A, Moodley $T$, et al. Inhaled long-acting $\beta_{2}$ agonists enhance glucocorticoid receptor nuclear translocation and efficacy in sputum macrophages in COPD. J Allergy Clin Immunol. 2013;132(5): 1166-1173.

25. Barnes PJ. Scientific rationale for inhaled combination therapy with long-acting $\beta_{2}$-agonists and corticosteroids. Eur Respir J. 2002;19(1): 182-191.

26. Calverley PM, Anderson JA, Celli B, et al. Salmeterol and fluticasone propionate and survival in chronic obstructive pulmonary disease. N Engl J Med. 2007;356(8):775-789.

27. Ferguson GT, Anzueto A, Fei R, Emmett A, Knobil K, Kalberg C. Effect of fluticasone propionate/salmeterol $(250 / 50 \mu \mathrm{g})$ or salmeterol $(50 \mu \mathrm{g})$ on COPD exacerbations. Respir Med. 2008;102(8):1099-1108.

28. Nannini LJ, Lasserson TJ, Poole P. Combined corticosteroid and longacting $\beta_{2}$-agonist in one inhaler versus long-acting $\beta_{2}$-agonists for chronic obstructive pulmonary disease. Cochrane Database Syst Rev. 2012; (9):CD006829.

29. Nannini LJ, Poole P, Milan SJ, Kesterton A. Combined corticosteroid and long-acting $\beta_{2}$-agonist in one inhaler versus inhaled corticosteroids alone for chronic obstructive pulmonary disease. Cochrane Database Syst Rev. 2013;(8):CD006826.

30. Oba Y, Lone NA. Comparative efficacy of inhaled corticosteroid and long-acting beta agonist combinations in preventing COPD exacerbations: a Bayesian network meta-analysis. Int J Chron Obstruct Pulmon Dis. 2014;9:469-479. 
31. Miravitlles M, D’Urzo A, Singh D, Koblizek V. Pharmacological strategies to reduce exacerbation risk in COPD: a narrative review. Respir Res. 2016;17(1):112.

32. Calverley PM, Eriksson G, Jenkins CR, et al. Early efficacy of budesonide/formoterol in patients with moderate-to-very-severe COPD. Int J Chron Obstruct Pulmon Dis. 2017;12:13-25.

33. Calverley PM, Postma DS, Anzueto AR, et al. Early response to inhaled bronchodilators and corticosteroids as a predictor of 12-month treatment responder status and COPD exacerbations. Int J Chron Obstruct Pulmon Dis. 2016;11:381-390.

34. Vogelmeier C, Hederer B, Glaab T, et al. Tiotropium versus salmeterol for the prevention of exacerbations of COPD. $N$ Engl J Med. 2011;364(12):1093-1103.

35. Decramer ML, Chapman KR, Dahl R, et al. Once-daily indacaterol versus tiotropium for patients with severe chronic obstructive pulmonary disease (INVIGORATE): a randomised, blinded, parallel-group study. Lancet Respir Med. 2013;1(7):524-533.

36. Trudo F, Kern DM, Davis JR, et al. Comparative effectiveness of budesonide/formoterol combination and tiotropium bromide among COPD patients new to these controller treatments. Int J Chron Obstruct Pulmon Dis. 2015;10:2055-2066.

37. Wedzicha JA, Calverley PM, Seemungal TA, et al. The prevention of chronic obstructive pulmonary disease exacerbations by salmeterol/ fluticasone propionate or tiotropium bromide. Am J Respir Crit Care Med. 2008;177(1):19-26.

38. Rodrigo GJ, Price D, Anzueto A, et al. LABA/LAMA combinations versus LAMA monotherapy or LABA/ICS in COPD: a systematic review and meta-analysis. Int J Chron Obstruct Pulmon Dis. 2017;12:907-922.

39. Wedzicha JA, Banerji D, Chapman KR, et al. Indacaterolglycopyrronium versus salmeterol-fluticasone for COPD. $N$ Engl $J$ Med. 2016;374(23):2222-2234.

40. Bafadhel M, McKenna S, Terry S, et al. Blood eosinophils to direct corticosteroid treatment of exacerbations of chronic obstructive pulmonary disease: a randomized placebo-controlled trial. Am J Respir Crit Care Med. 2012;186(1):48-55.

41. Siddiqui SH, Guasconi A, Vestbo J, et al. Blood eosinophils: a biomarker of response to extrafine beclomethasone/formoterol in chronic obstructive pulmonary disease. Am J Respir Crit Care Med. 2015;192(4):523-525.

42. Bafadhel M, Peterson S, de Blas MA, et al. Predictors of exacerbation risk and response to budesonide in patients with chronic obstructive pulmonary disease: a post-hoc analysis of three randomised trials. Lancet Respir Med. 2018;6(2):117-126.

43. Tashkin DP, Wechsler ME. Role of eosinophils in airway inflammation of chronic obstructive pulmonary disease. Int J Chron Obstruct Pulmon Dis. 2018;13:335-349.

44. Cheng SL, Lin CH. Effectiveness using higher inhaled corticosteroid dosage in patients with COPD by different blood eosinophilic counts. Int J Chron Obstruct Pulmon Dis. 2016;11:2341-2348.

45. Calverley P, Vlies B. A rational approach to single, dual and triple therapy in COPD. Respirology. 2016;21(4):581-589.

46. Watz H, Tetzlaff $\mathrm{K}$, Wouters EF, et al. Blood eosinophil count and exacerbations in severe chronic obstructive pulmonary disease after withdrawal of inhaled corticosteroids: a post-hoc analysis of the WISDOM trial. Lancet Respir Med. 2016;4(5):390-398.

47. Pascoe S, Locantore N, Dransfield MT, Barnes NC, Pavord ID. Blood eosinophil counts, exacerbations, and response to the addition of inhaled fluticasone furoate to vilanterol in patients with chronic obstructive pulmonary disease: a secondary analysis of data from two parallel randomised controlled trials. Lancet Respir Med. 2015;3(6):435-442.

48. Hastie AT, Martinez FJ, Curtis JL, et al. Association of sputum and blood eosinophil concentrations with clinical measures of COPD severity: an analysis of the SPIROMICS cohort. Lancet Respir Med. 2017; 5(12):956-967.

49. Christenson SA, Steiling K, van den Berge M, et al. Asthma-COPD overlap: clinical relevance of genomic signatures of type 2 inflammation in chronic obstructive pulmonary disease. Am J Respir Crit Care Med. 2015;191(7):758-766.
50. Tamada T, Sugiura H, Takahashi T, et al. Biomarker-based detection of asthma-COPD overlap syndrome in COPD populations. Int J Chron Obstruct Pulmon Dis. 2015;10:2169-2176.

51. Alshabanat A, Zafari Z, Albanyan O, Dairi M, Fitzgerald JM. Asthma and COPD overlap syndrome (ACOS): a systematic review and meta analysis. PLoS One. 2015;10(9): 0136065.

52. Tashkin DP, Murray RP. Smoking cessation in chronic obstructive pulmonary disease. Respir Med. 2009;103(7):963-974.

53. Simmons MS, Connett JE, Nides MA, et al. Smoking reduction and the rate of decline in $\mathrm{FEV}_{1}$ : results from the Lung Health Study. Eur Respir J. 2005;25(6):1011-1017.

54. Tamimi A, Serdarevic D, Hanania NA. The effects of cigarette smoke on airway inflammation in asthma and COPD: therapeutic implications. Respir Med. 2012;106(3):319-328.

55. Hoonhorst SJ, ten Hacken NH, Vonk JM, et al. Steroid resistance in COPD? Overlap and differential anti-inflammatory effects in smokers and ex-smokers. PLoS One. 2014;9(2):e87443.

56. Sohal SS, Reid D, Soltani A, et al. Changes in airway histone deacetylase 2 in smokers and COPD with inhaled corticosteroids: a randomized controlled trial. PLoS One. 2013;8(5):e64833.

57. van Overveld FJ, Demkow U, Górecka D, de Backer WA, Zieliński J. Differences in responses upon corticosteroid therapy between smoking and non-smoking patients with COPD. $J$ Physiol Pharmacol. 2006; 57 Suppl 4:273-282.

58. Tashkin DP, Murray HE, Skeans M, Murray RP. Skin manifestations of inhaled corticosteroids in COPD patients: results from Lung Health Study II. Chest. 2004;126(4):1123-1133.

59. Eichenhorn MS, Wise RA, Madhok TC, et al. Lack of long-term adverse adrenal effects from inhaled triamcinolone: Lung Health Study II. Chest. 2003;124(1):57-62.

60. Cumming RG, Mitchell P, Leeder SR. Use of inhaled corticosteroids and the risk of cataracts. N Engl J Med. 1997;337(1):8-14.

61. Wang JJ, Rochtchina E, Tan AG, Cumming RG, Leeder SR, Mitchell P. Use of inhaled and oral corticosteroids and the long-term risk of cataract. Ophthalmology. 2009;116(4):652-657.

62. Miller DP, Watkins SE, Sampson T, Davis KJ. Long-term use of fluticasone propionate/salmeterol fixed-dose combination and incidence of cataracts and glaucoma among chronic obstructive pulmonary disease patients in the UK General Practice Research Database. Int $J$ Chron Obstruct Pulmon Dis. 2011;6:467-476.

63. Rennard SI, Tashkin DP, McElhattan J, et al. Efficacy and tolerability of budesonide/formoterol in one hydrofluoroalkane pressurized metereddose inhaler in patients with chronic obstructive pulmonary disease: results from a 1-year randomized controlled clinical trial. Drugs. 2009;69(5):549-565.

64. Silva DR, Coelho AC, Dumke A, et al. Osteoporosis prevalence and associated factors in patients with COPD: a cross-sectional study. Respir Care. 2011;56(7):961-968.

65. Ferguson GT, Calverley PMA, Anderson JA, et al. Prevalence and progression of osteoporosis in patients with COPD: results from the Towards a Revolution in COPD Health study. Chest. 2009;136(6):1456-1465.

66. Loke YK, Cavallazzi R, Singh S. Risk of fractures with inhaled corticosteroids in COPD: systematic review and meta-analysis of randomised controlled trials and observational studies. Thorax. 2011;66(8):699-708.

67. Scanlon PD, Connett JE, Wise RA, et al. Loss of bone density with inhaled triamcinolone in Lung Health Study II. Am J Respir Crit Care Med. 2004;170(12):1302-1309.

68. Romme EA, Geusens P, Lems WF, et al. Fracture prevention in COPD patients: a clinical 5-step approach. Respir Res. 2015;16:32.

69. Bourbeau J, Aaron SD, Barnes NC, Davis KJ, Lacasse Y, Nadeau G. Evaluating the risk of pneumonia with inhaled corticosteroids in COPD: retrospective database studies have their limitations SA. Respir Med. 2017;123:94-97.

70. DiSantostefano RL, Sampson T, Le HV, Hinds D, Davis KJ, Bakerly ND. Risk of pneumonia with inhaled corticosteroid versus long-acting bronchodilator regimens in chronic obstructive pulmonary disease: a new-user cohort study. PLoS One. 2014;9(5):e97149. 
71. Singh S, Amin AV, Loke YK. Long-term use of inhaled corticosteroids and the risk of pneumonia in chronic obstructive pulmonary disease: a meta-analysis. Arch Intern Med. 2009;169(3):219-229.

72. Sin DD, Tashkin D, Zhang X, et al. Budesonide and the risk of pneumonia: a meta-analysis of individual patient data. Lancet. 2009;374(9691): $712-719$.

73. Janson C, Larsson K, Lisspers KH, et al. Pneumonia and pneumonia related mortality in patients with COPD treated with fixed combinations of inhaled corticosteroid and long acting $\beta_{2}$ agonist: observational matched cohort study (PATHOS). BMJ. 2013;346:f3306.

74. Morjaria JB, Rigby A, Morice AH. Inhaled corticosteroid use and the risk of pneumonia and COPD exacerbations in the UPLIFT study. Lung. 2017;195(3):281-288.

75. Kew KM, Seniukovich A. Inhaled steroids and risk of pneumonia for chronic obstructive pulmonary disease. Cochrane Database Syst Rev. 2014;3:CD010115.

76. Janson C, Stratelis G, Miller-Larsson A, Harrison TW, Larsson K. Scientific rationale for the possible inhaled corticosteroid intraclass difference in the risk of pneumonia in COPD. Int $J$ Chron Obstruct Pulmon Dis. 2017;12:3055-3064.

77. Yang HH, Lai CC, Wang YH, et al. Severe exacerbation and pneumonia in COPD patients treated with fixed combinations of inhaled corticosteroid and long-acting $\beta_{2}$ agonist. Int J Chron Obstruct Pulmon Dis 2017; 12:2477-2485.

78. Singh D, Miravitlles M, Vogelmeier C. Chronic obstructive pulmonary disease individualized therapy: tailored approach to symptom management. Adv Ther. 2017;34(2):281-299.

79. Magnussen H, Disse B, Rodriguez-Roisin R, et al. Withdrawal of inhaled glucocorticoids and exacerbations of COPD. $N$ Engl J Med. 2014;371(14):1285-1294.

80. Rossi A, Guerriero M, Corrado A. Withdrawal of inhaled corticosteroids can be safe in COPD patients at low risk of exacerbation: a real-life study on the appropriateness of treatment in moderate COPD patients (OPTIMO). Respir Res. 2014;15:77.

81. Singh D, Papi A, Corradi M, et al. Single inhaler triple therapy versus inhaled corticosteroid plus long-acting $\beta 2$-agonist therapy for chronic obstructive pulmonary disease (TRILOGY): a double-blind, parallel group, randomised controlled trial. Lancet. 2016;388(10048): 963-973.

82. Lipson DA, Barnacle H, Birk R, et al. FULFIL trial: once-daily triple therapy for patients with chronic obstructive pulmonary disease. Am J Respir Crit Care Med. 2017;196(4):438-446.

83. Lipson DA, Barnhart F, Brealey N, et al. Once-daily single-inhaler triple versus dual therapy in patients with COPD. NEngl J Med. 2018;378(18) $1671-1680$.
84. Kwak MS, Kim E, Jang EJ, Kim HJ, Lee CH. The efficacy and safety of triple inhaled treatment in patients with chronic obstructive pulmonary disease: a systematic review and meta-analysis using Bayesian methods. Int J Chron Obstruct Pulmon Dis. 2015;10:2365-2376.

85. Mäkelä MJ, Backer V, Hedegaard M, Larsson K. Adherence to inhaled therapies, health outcomes and costs in patients with asthma and COPD. Respir Med. 2013;107(10):1481-1490.

86. Brusselle G, Price D, Gruffydd-Jones K, et al. The inevitable drift to triple therapy in COPD: an analysis of prescribing pathways in the UK. Int J Chron Obstruct Pulmon Dis. 2015;10:2207-2217.

87. Simeone JC, Luthra R, Kaila S, et al. Initiation of triple therapy maintenance treatment among patients with COPD in the US. Int J Chron Obstruct Pulmon Dis. 2017;12:73-83.

88. Mannino D, Yu TC, Zhou H, Higuchi K. Effects of GOLD-adherent prescribing on COPD symptom burden, exacerbations, and health care utilization in a real-world setting. Chronic Obstr Pulm Dis. 2015;2(3): $223-235$.

89. Trelegy Ellipta. (fluticasone furoate, umeclidinium, and vilanterol inhalation powder) [package insert]. Research Triangle Park (NC): GlaxoSmithKline; 2017.

90. National Institute for Health and Care Excellence. Chronic Obstructive Pulmonary Disease: Management of Adults With Chronic Obstructive Pulmonary Disease in Primary and Secondary Care. London: NICE; 2009.

91. Han MK, Quibrera PM, Carretta EE, et al. Frequency of exacerbations in patients with chronic obstructive pulmonary disease: an analysis of the SPIROMICS cohort. Lancet Respir Med. 2017;5(8):619-626.

92. Hurst JR, Vestbo J, Anzueto A, et al. Susceptibility to exacerbation in chronic obstructive pulmonary disease. $N$ Engl J Med. 2010;363(12): 1128-1138.

93. Pavord ID, Chanez P, Criner GJ, et al. Mepolizumab for eosinophilic chronic obstructive pulmonary disease. N Engl J Med. 2017;377(17): 1613-1629.

94. AstraZeneca. AstraZeneca provides update on GALATHEA Phase III trial for Fasenra in chronic obstructive pulmonary disease [press release]. 2018 May 11. Available from: https://www.astrazeneca.com/ media-centre/press-releases/2018/astrazeneca-provides-update-ongalathea-phase-iii-trial-for-fasenra-in-chronic-obstructive-pulmonarydisease-11052018.html. Accessed July 12, 2018.

95. AstraZeneca. Update on TERRANOVA Phase III trial for Fasenra in chronic obstructive pulmonary disease [press release] 2018 May 30. Available from: https://www.astrazeneca.com/mediacentre/press-releases/2018/update-on-terranova-phase-iii-trial-forfasenra-in-chronic-obstructive-pulmonary-disease-30052018.html. Accessed July 12, 2018.
International Journal of COPD

\section{Publish your work in this journal}

The International Journal of COPD is an international, peer-reviewed journal of therapeutics and pharmacology focusing on concise rapid reporting of clinical studies and reviews in COPD. Special focus is given to the pathophysiological processes underlying the disease, intervention programs, patient focused education, and self management protocols.

\section{Dovepress}

This journal is indexed on PubMed Central, MedLine and CAS. The manuscript management system is completely online and includes a very quick and fair peer-review system, which is all easy to use. Visit http://www.dovepress.com/testimonials.php to read real quotes from published authors. 